\title{
EFEITO DE FUNGOS MICORRÍZICOS ARBUSCULARES NO CRESCIMENTO DE MUDAS DE Leucaena leucocephala (LAM.) DE WIT. EM SOLOS DE CAATINGA SOB IMPACTO DE MINERAÇÃO DE COBRE ${ }^{1}$
}

\author{
Cláudia Elizabete de Lima Lins ${ }^{2}$, Leonor Costa Maia ${ }^{2,4}$, Uided Maaze Tiburcio Cavalcante ${ }^{2}$ e Everardo \\ Valadares de Sá Barreto Sampaio ${ }^{3,4}$
}

\begin{abstract}
RESUMO - Os fungos micorrízicos arbusculares (FMA) podem conferir às plantas maior tolerância a metais pesados e têm sido indicados para uso em processos de revegetação. Foi avaliado o efeito de FMA no crescimento de mudas de Leucaena leucocephala (leucena), em solos de áreas de caatinga impactados por mineração de cobre (Mineradora Caraíba, Município de Jaguarari, Bahia). O delineamento foi do tipo inteiramente casualizado, em arranjo fatorial $3 \times 4$, correspondendo ao substrato das áreas de empréstimo (local em que a camada superficial do solo foi removida) e de rejeito de cobre, ao solo de caatinga preservada e a quatro tratamentos de inoculação (controle não-inoculado, inoculado com Glomus etunicatum, com Acaulospora longula e com a mistura dos dois fungos), com cinco repetições. Independentemente do tratamento de inoculação, o substrato da área de empréstimo mostrou-se mais indicado para o preparo de mudas de leucena, enquanto o da área de rejeito foi inviável para o cultivo dessa planta e estabelecimento da associação micorrízica. Embora infectivo, G. etunicatum foi ineficiente em promover o crescimento de leucena nas áreas impactadas, enquanto os FMA nativos, $A$. longula e a mistura dos fungos contribuíram para o desenvolvimento das mudas.
\end{abstract}

Palavras-chave: Áreas degradadas, cobre, leucena e micorriza arbuscular.

\section{EFFECT OF ARBUSCULAR MYCORRHIZAL FUNGI ON GROWTH OF Leucaena leucocephala (LAM.) DE WIT. SEEDLINGS ON CAATINGA SOILS DEGRADED BY COPPER MINING}

\begin{abstract}
The arbuscular mycorrhizal fungi (AMF) can promote plant tolerance to heavy metals and have been indicated for use in revegetation processes. The effect of native and introduced AMF on the growth of seedlings of Leucaena leucocephala on soils of caatinga biome impacted by copper mining (Mineração Caraíba, Jaguarari Municipality, Bahia State) was evaluated. The experiment was set up in a complete randomized design, in a $3 \times 4$ factorial arrangement, considering soil from preserved caatinga and substrates of a site from which the topsoil was removed and a site which received copper waste; and four inoculation treatments (uninoculated control, inoculated with Glomus etunicatum, Acaulospora longula, and a mixture of the two fungi), with five replicates. Independently of the inoculation treatment, the area where the topsoil was removed was more indicated for preparing the seedlings of leucaena, while the soil from the waste site was not suitable for growth of this plant and the establishment of mycorrhizal association. Although infective, G. etunicatum was not efficient in promoting growth of leucaena in the impacted areas, while the native AMF, A. longula and the mixture of fungi contributed to the development of the seedlings.
\end{abstract}

Keywords: Arbuscular mycorrhiza, copper, disturbed area and leucaena.

\footnotetext{
${ }^{1}$ Recebido em 30.10.2006 e aceito para publicação em 31.01.2007.

${ }^{2}$ Departamento de Micologia da Universidade Federal de Pernambuco, 50670-420 Recife, PE. E-mail:<claudiaell@ hotmail.com; leonorcmaia@yahoo.com.br; umaaze@yahoo.com.br.

${ }^{3}$ Departamento de Energia Nuclear da Universidade Federal de Pernambuco, 50740-540 Recife, PE. E-mail:<esampaio@ufpe.br>.

${ }^{4}$ Bolsista CNPq.
} 


\section{INTRODUÇÃO}

O Nordeste do Brasil é caracterizado pelo clima semi-árido, com solos rasos e presença de vegetação seca e arbustiva, denominada Caatinga, que se estende por 6 a $9 \times 10^{5} \mathrm{~km}^{2}$ da região (RODAL e SAMPAIO, 2002). Os efeitos climáticos, como a seca, dificultam a manutenção e desenvolvimento das plantas pela deterioração do solo, escassez de água e diminuição da diversidade de espécies (DRUMOND et al., 2004). A caatinga sofre, também, processo de degradação pela mineração, com a retirada da vegetação natural e a movimentação do solo, gerando subáreas isentas da camada superficial do solo ou com considerável quantidade de rejeitos. A retirada de minério a céu aberto, sem o retorno dos horizontes superficiais, conduz a um substrato remanescente formado por uma massa heterogênea de material geológico que, por intemperismo, leva à formação de horizontes superficiais, promovendo a acidificação ou alcalinização do sistema e contribuindo para o distúrbio da área (DIAS, 1998).

As leguminosas arbóreas possuem vasto sistema radicular e elevada produção de biomassa (CAMPELLO, 1998), que contribui para a retenção de água e sais minerais. A leucena, Leucaena leucocephala (LAM.) de Wit., é uma das leguminosas arbóreas mais cultivadas do mundo, pois se adapta a diversos tipos de solos, sendo tolerantes à seca e à temperatura variável (16 a $32{ }^{\circ} \mathrm{C}$ ). Além de ser utilizada para melhoria dos solos, é aproveitada com diferentes propósitos, incluindo a produção de madeira, lenha, forragem e adubo orgânico (PARROTA, 1992).

Interações ecológicas vêm sendo estudadas utilizando leguminosas arbóreas e fungos micorrízicos arbusculares (FMA) no estabelecimento de plantas em ambientes áridos (DUPONNOIS et al., 2005) e erodidos (FAGBOLA et al., 2001), sistemas agroflorestais (DIAGNE et al., 2001; INGLEBY et al., 1997) e áreas degradadas por mineração (LINS et al., 2006; MA et al., 2006). A presença desses fungos é fundamental para a regeneração de ecossistemas impactados, por contribuírem para a sobrevivência e reprodução de espécies arbóreas onde a fertilidade do solo é baixa (CAPRONI et al., 2005; RAO e TARAFDAR, 1998). Trabalhos utilizando leucena e FMA têm confirmado a sua alta dependência da micorrização (HABTE e MANJUNATH, 1987) e do benefício desses fungos no crescimento dessa planta (MUTHUKUMAR e UDAIYAN, 2000; BRANDON e SHELTON, 1997).

R. Árvore, Viçosa-MG, v.31, n.2, p.355-363, 2007
O prejuízo à vegetação e o baixo potencial de infectividade dos FMA na área de caatinga afetada por atividade mineradora torna necessária a revegetação do local com mudas de leguminosas noduladas e micorrizadas, para a conservação da diversidade vegetal, animal e microbiana (SILVAet al., 2001). Assim, foi avaliado o efeito de FMA no crescimento de mudas de leucena em solos de caatinga que sofreram impacto por mineração.

\section{MATERIAL E MÉTODOS}

Foram utilizados solos e substratos de áreas da Mineração Caraíba, Município de Jaguararí, Bahia (9॰51'43" latitude sul e 39॰53'50"' longitude oeste), onde é feita a extração de cobre. A área é em geral plana, com rochas emergentes, precipitação média anual de $400 \mathrm{~mm}$, clima tropical semi-árido e vegetação típica de caatinga. Amostras de solos e substrato foram coletadas em três subáreas: caatinga preservada, cujo solo foi utilizado como controle (1), e duas com distúrbios ambientais provocados pela mineradora; uma de rejeito (2); e outra de empréstimo (3). A subárea de rejeito, com aproximadamente 600 ha, compreende a bacia de rejeito da mineradora, onde é depositado o pó da rocha da qual foi extraído o cobre. A subárea de empréstimo é caracterizada por não possuir a camada superficial do solo, retirada para encobrir restos de rochas de outra subárea também sob impacto. Essa subárea é constituída por fragmentos com aproximadamente três hectares, distribuídos irregularmente dentro da área da mineradora. De cada subárea foram coletadas, em pontos aleatórios, 10 amostras de solo (caatinga) e de substrato (áreas de empréstimo e de depósito de rejeito), na profundidade de 0,05 a 0,20 m. As amostras de cada subárea foram homogeneizadas e analisadas quanto a características físicas e químicas (Tabela 1) no Laboratório de Análises de Solos da Embrapa SemiÁrido, Petrolina, PE, seguindo-se a metodologia da Embrapa (1997): P, Cu, Fe, Zn e Mn extraídos por Mehlich1 , o primeiro determinado por colorimetria e os demais por espectrofotometria de absorção atômica; Al por extração com $\mathrm{KCl} 1 \mathrm{~mol} \mathrm{~L}^{-1}$ e titulação; $\mathrm{pH}$ em água (solo : 2,5 água, v/v) por potenciometria; matéria orgânica (M.O.) pelo método de oxidação úmida e titulação; e granulometria pelo método do densímetro.

Sementes de Leucaena leucocephala (Lam.) de Wit. foram obtidas no Banco de Sementes da Empresa 
Pernambucana de Pesquisa Agropecuária (IPA), escarificadas e mergulhadas em água destilada, por três horas, para quebra de dormência, e adicionadas de um inoculante turfoso contendo rizóbio específico (Bradyrhizobium sp.), fornecido pelo Centro Nacional de Pesquisa em Agrobiologia (CNPAB/Embrapa), sendo as sementes colocadas em bandejas com solo esterilizado e esterco bovino curtido, na proporção de 9:1.

Dez dias após a germinação, foram inoculados 100 esporos por planta de Glomus etunicatum Becker e Gerd. ou Acaulospora longula Spain e Schenck, isoladamente e em mistura (50 esporos de cada isolado), por ocasião do transplantio das mudas para sacos plásticos contendo $2 \mathrm{~kg}$ de solo ou dos substratos. Uma vez que o solo e os substratos empregados no experimento não foram esterilizados, o tratamento não inoculado (controle) possuía FMA nativos. As plantas foram mantidas em casa de vegetação (temperatura: 23 a $32{ }^{\circ} \mathrm{C}$ e umidade relativa do ar: 50 a $81 \%$ ) e regadas em dias alternados.

Os isolados de Glomus etunicatum (UFPE 06) e de Acaulospora longula (UFPE 08) foram obtidos na coleção de culturas de FMA do Laboratório de Micorrizas da Universidade Federal de Pernambuco (UFPE). Os esporos foram extraídos do solo-inóculo por decantação e peneiramento úmido (GERDEMANN e NICOLSON, 1963), seguido por centrifugação em água e em sacarose 40\% (JENKINS, 1964), lavados e separados em grupos de 100 ou 50 esporos cada.

O experimento foi colhido 110 dias após a inoculação, sendo avaliados: altura das plantas, número de folhas, diâmetro do caule a $3 \mathrm{~cm}$ do solo, matéria seca da parte aérea e da raiz, colonização total das raízes, quantificação das estruturas micorrízicas (hifas, vesículas e arbúsculos) e eficiência da micorriza (EM). Parte aérea e raízes das plantas foram secadas em estufa $\left(65^{\circ} \mathrm{C}\right)$ até peso constante. Para avaliação da colonização, $0,5 \mathrm{~g}$ de raízes frescas de cada repetição foi clarificado, corado (KOSKE e GEMMA, 1989) e observado ao microscópio, num total de 50 segmentos de $1 \mathrm{~cm}$ por repetição (GIOVANNETTI e MOSSE, 1980), para contagem de estruturas formadas pelos FMA (hifas, arbúsculos e vesículas). A EM foi calculada pela fórmula que considera a diferença entre a matéria seca total da planta colonizada e da planta não-colonizada, dividida pela matéria seca total da planta colonizada (BAGYARAJ et al., 1988).

O delineamento foi do tipo inteiramente casualizado, em arranjo fatorial $3 \times 4$, considerando-se: três substratos (da área de rejeito e da área de empréstimo e solo da caatinga nativa) e quatro tratamentos de inoculação (controle não-inoculado, inoculado com G. etunicatum, com A. longula e com a mistura dos dois fungos), com cinco repetições. Os potes com os respectivos tratamentos foram distribuídos em casa de vegetação após sorteio e rearranjados semanalmente. Os dados foram submetidos à análise de variância e as médias, comparadas pelo teste LSD a 5\% de probabilidade, utilizando-se o programa Statistica (STATSOFT, 1995). Para análise, os dados de colonização de raízes foram transformados em Arco sen $\sqrt{ } \mathrm{x} / 100$.

\section{RESULTADOS E DISCUSSÃO}

As plantas cultivadas no substrato da subárea de rejeito, mesmo inoculadas, apresentaram menor crescimento em todos os parâmetros avaliados, exceto para o número de folhas que, em geral, foi semelhante ao do tratamento com solo da caatinga preservada e inferior ao da área de empréstimo (Tabela 2).

Quadro 1 - Características físicas e químicas do solo de área de caatinga e de substratos (0,05-0,20 m de profundidade) de local em que a camada superficial do solo foi removida (empréstimo) e de local que recebeu rejeito de cobre (Mineração Caraíba, Município de Jaguarari, Bahia)

Table 1 - Physical and chemical characteristics of soil from a caatinga area and substrates $(0.05-0.20 \mathrm{~m}$ depth) from a site where the topsoil was removed and a site which received copper waste (Mineração Caraíba, Jaguarari Municipality, Bahia State)

\begin{tabular}{|c|c|c|c|c|c|c|c|c|c|c|c|}
\hline \multirow[b]{2}{*}{ Subáreas } & $\mathrm{P}$ & $\mathrm{Cu}$ & $\mathrm{Fe}$ & $\mathrm{Zn}$ & Mn & \multirow{2}{*}{$\frac{\mathrm{Al}}{\mathrm{cmol}_{\mathrm{c}} \mathrm{L}^{-1}}$} & \multirow[t]{2}{*}{$\mathrm{pH}$} & \multirow{2}{*}{$\frac{\mathrm{MO}}{\mathrm{g} \mathrm{dm}^{-3}}$} & Areia & Silte & Argila \\
\hline & & & $\mathrm{ng} \mathrm{dm}$ & & & & & & \multicolumn{3}{|c|}{$\mathrm{g} \mathrm{kg}^{-1}$} \\
\hline Caatinga & 10 & 0,4 & 216 & 4,6 & 3,5 & 0,05 & 6,1 & 27,3 & 620 & 240 & 140 \\
\hline Empréstimo & 29 & 7,4 & 91,7 & 2,1 & 49,0 & 0,05 & 6,7 & 11,9 & 650 & 190 & 160 \\
\hline Rejeito & 70 & 483 & 672 & 3,6 & 53,3 & 0,00 & 7,4 & 5,7 & 930 & 30 & 40 \\
\hline
\end{tabular}


Quadro 2 - Crescimento de mudas de Leucaena leucocephala após 110 dias da inoculação com fungos micorrízicos arbusculares (FMA) em solo da caatinga e substratos degradados por mineração de cobre

Table 2 - Growth of Leucaena leucocephala seedlings 110 days after the inoculation with arbuscular mycorrhizal fungi $(A M F)$ in caatinga soil and in substrates degraded by copper mining

\begin{tabular}{|c|c|c|c|c|}
\hline \multirow[t]{2}{*}{ Subárea } & \multicolumn{4}{|c|}{ Tratamento de Inoculação } \\
\hline & $\begin{array}{c}\text { Controle } \\
\text { (FMA nativos) }\end{array}$ & G. etunicatum & A. longula & $\begin{array}{c}\text { Mistura de FMA } \\
(\text { G. etunicatum }+ \text { A. longula })\end{array}$ \\
\hline & \multicolumn{4}{|c|}{ Altura $(\mathrm{cm})$} \\
\hline Caatinga & $66,0 \mathrm{aA}$ & $70,6 \mathrm{aA}$ & $74,6 \mathrm{aA}$ & $66,2 \mathrm{bA}$ \\
\hline Empréstimo & $81,9 \mathrm{aAB}$ & $75,2 \mathrm{aB}$ & $95,6 \mathrm{aA}$ & $94,6 \mathrm{aA}$ \\
\hline Rejeito & $19,5 \mathrm{bA}$ & $15,2 \mathrm{bA}$ & $18,1 \mathrm{bA}$ & $28,3 \mathrm{cA}$ \\
\hline \multirow[t]{2}{*}{$\overline{\mathrm{CV}(\%)}$} & \multicolumn{4}{|c|}{19,7} \\
\hline & \multicolumn{4}{|c|}{ Número de folhas } \\
\hline Caatinga & $48,8 \mathrm{bB}$ & $76,0 \mathrm{aA}$ & $75,4 \mathrm{bA}$ & $74,0 \mathrm{bA}$ \\
\hline Empréstimo & $102,4 \mathrm{aA}$ & $102,8 \mathrm{aA}$ & $120,8 \mathrm{aA}$ & $123,6 \mathrm{aA}$ \\
\hline Rejeito & $32,6 \mathrm{bA}$ & $23,6 \mathrm{bA}$ & $31,0 \mathrm{bA}$ & $38,4 \mathrm{bA}$ \\
\hline \multirow[t]{2}{*}{$\overline{\mathrm{CV}(\%)}$} & \multicolumn{4}{|c|}{28,9} \\
\hline & \multicolumn{4}{|c|}{ Diâmetro do caule (mm) } \\
\hline Caatinga & $0,642 \mathrm{aA}$ & $0,692 \mathrm{aA}$ & $0,692 \mathrm{aA}$ & $0,686 \mathrm{aA}$ \\
\hline Empréstimo & $0,678 \mathrm{aA}$ & $0,670 \mathrm{aA}$ & $0,718 \mathrm{aA}$ & $0,756 \mathrm{aA}$ \\
\hline Rejeito & $0,374 \mathrm{bB}$ & $0,356 \mathrm{bB}$ & $0,448 \mathrm{bA}$ & $0,464 \mathrm{bA}$ \\
\hline \multirow[t]{2}{*}{$\overline{\mathrm{CV}(\%)}$} & \multicolumn{4}{|c|}{12,2} \\
\hline & \multicolumn{4}{|c|}{ Matéria seca da parte aérea $(\mathrm{g})$} \\
\hline Caatinga & $5,040 \mathrm{bA}$ & $7,014 \mathrm{aA}$ & $7,012 \mathrm{bA}$ & $6,752 \mathrm{bA}$ \\
\hline Empréstimo & $8,628 \mathrm{aB}$ & $7,922 \mathrm{aB}$ & $12,600 \mathrm{aA}$ & $11,758 \mathrm{aA}$ \\
\hline Rejeito & $0,982 \mathrm{cA}$ & $0,886 \mathrm{bA}$ & $1,104 \mathrm{cA}$ & $1,510 \mathrm{cA}$ \\
\hline \multirow[t]{2}{*}{$\mathrm{CV}(\%)$} & \multicolumn{4}{|c|}{26,9} \\
\hline & \multicolumn{4}{|c|}{ Matéria seca da raiz $(\mathrm{g})$} \\
\hline Caatinga & $1,824 \mathrm{abB}$ & $3,076 \mathrm{aA}$ & $3,162 \mathrm{aA}$ & $3,568 \mathrm{aA}$ \\
\hline Empréstimo & $2,840 \mathrm{aB}$ & $3,200 \mathrm{aB}$ & $4,214 \mathrm{aA}$ & $4,602 \mathrm{aA}$ \\
\hline Rejeito & $0,466 \mathrm{bA}$ & $0,400 \mathrm{bA}$ & $0,588 \mathrm{bA}$ & $0,734 \mathrm{bA}$ \\
\hline$\overline{\mathrm{CV}(\%)}$ & \multicolumn{4}{|c|}{27,4} \\
\hline
\end{tabular}

Valores seguidos das mesmas letras, maiúsculas nas linhas e letras minúsculas nas colunas, dentro de cada variável, não diferem entre si pelo teste LSD a $5 \%$ de probabilidade.

Os elevados teores de ferro-Fe, de manganêsMn e, principalmente, de cobre- $\mathrm{Cu}$, na subárea de rejeito, respectivamente $672 ; 53,3$; e $483 \mathrm{mg} \mathrm{dm}^{-3}$, podem ter inibido o crescimento das plantas, em conseqüência da maior absorção desses metais, como também observado por Siqueira et al. (1999) em mudas de árvores transplantadas. Do mesmo modo, esses metais devem ter inibido a atuação dos FMA. Em estudo realizado anteriormente na mesma subárea de rejeito, Silva et al. (2001) encontraram apenas um esporo de FMA por $100 \mathrm{~g}$ de solo na estação chuvosa e nenhum na estação seca, o que indica que a presença dos elementos mencionados, em teores elevados, afeta negativamente os FMA nativos. Essas concentrações podem também ter afetado os fungos inoculados (G. etunicatum e A. longula), prejudicando o estabelecimento da simbiose.
O crescimento das plantas associadas a $G$. etunicatum e A. longula no substrato da subárea de empréstimo foi, em geral, semelhante ao do tratamento com solo de caatinga preservada. As mudas na subárea de empréstimo produziram mais folhas e maior matéria seca da parte aérea do que as mudas cultivadas no solo da subárea de caatinga e no substrato da subárea de rejeito, com os FMA introduzidos e os nativos, exceto com G. etunicatum, cuja produção foi semelhante à do solo da caatinga. Comparando os tratamentos de inoculação para a subárea de empréstimo, verificouse que as plantas associadas apenas com G. etunicatum mostraram menor altura e com os FMA nativos e $G$. etunicatum, menor produção de matéria seca de parte aérea e de raiz (Tabela 2). Embora Silva et al. (2001) tenham verificado nessa subárea de empréstimo, em solo coletado no mesmo período, elevado número de 
propágulos infectivos de FMA nativos (36 100 $\mathrm{g} \mathrm{solo}^{-1}$ ), os FMA introduzidos em $A$. longula e a mistura foram eficazes, em relação aos demais tratamentos de inoculação, em promover o crescimento das mudas de leucena.

Na subárea de caatinga preservada, plantas inoculadas com os FMA introduzidos foram favorecidas na formação de folhas, diferindo significativamente do tratamento com fungos nativos. Nas áreas de empréstimo e de rejeito não houve diferença entre os tratamentos de inoculação na produção foliar (Tabela 2). A matéria seca da parte aérea das plantas mantidas em solo de caatinga também não diferiu entre os tratamentos com FMA nativos e introduzidos.

Maior porcentual de colonização por FMA em raízes de leucena ocorreu, em geral, nas plantas cultivadas em solo de caatinga preservada. A colonização total nas raízes de leucena foi elevada $(>62,4 \%)$ e próxima entre os tratamentos com solo da subárea de caatinga e substrato da subárea de empréstimo, sendo em alguns casos superiores a $90 \%$. A produção de vesículas foi maior nas plantas mantidas em solo da caatinga do que no substrato da subárea de empréstimo, com exceção do tratamento G. etunicatum. A colonização por arbúsculos foi semelhante nos tratamentos com solo da subárea de caatinga e substrato da subárea de empréstimo, mas houve tendência para maior produção no tratamento com solo da caatinga. Em todos os tratamentos de inoculação (incluindo o controle, com fungos nativos), as plantas foram colonizadas em proporções semelhantes nas três variáveis (colonização total, por vesículas e por arbúsculos). No entanto, no tratamento com substrato da subárea de rejeito as plantas não foram colonizadas (Tabela 3). A toxidez do cobre sobre os FMA pode ter impedido a colonização das raízes de leucena nesse substrato. O mesmo ocorreu em raízes de Agrostis capillares L. (A. tenuis Sibth.) cultivada em solo também contaminado por cobre (GRIFFIOEN et al., 1994). De acordo com Siqueira et al. (1999), o fato pode estar relacionado à absorção de metais pesados pelas plantas. Efeito negativo de metais pesados sobre o crescimento do micélio externo e a produção de arbúsculos por Glomus sp. e Glomus mosseae (Nicolson e Gerd.) Gerd. e Trappe foi mencionado por Del Val et al. (1999).
A visualização dos arbúsculos foi difícil, mas vesículas de variadas formas foram encontradas nos tratamentos inoculados. Raízes de árvores crescidas em solo contaminado por cromo - $\mathrm{Cr}$ também apresentaram poucos arbúsculos e muitas vesículas intracelulares, irregulares e lobadas, características de espécies de Acaulospora (KHAN, 2001). A presença de muitas vesículas e poucas células auxiliares nos tratamentos com fungos nativos indica que eles são constituídos primordialmente por espécies de Glomus e de Acaulospora, pois as de Gigasporaceae não formam vesículas (STADDON e FITTER, 2001). Silva et al. (2005) verificaram que $70 \%$ das espécies de FMA encontradas na mesma área deste estudo pertenciam a Glomus. Espécies de Gigaspora estão mais presentes em solos com pH ácido (MAIA e TRUFEM, 1990), enquanto as de Glomus e de Acaulospora têm sido mais registradas em solos com pH igual ou acima de 6,1 (SCHENCK e SIQUEIRA, 1987). O pH do solo da caatinga $(6,1)$ e do substrato da subárea de empréstimo $(6,7)$ pode ter favorecido a maior ocorrência desses dois gêneros.

No presente trabalho, o isolado de $G$. etunicatum introduzido não foi capaz de incrementar o crescimento das plantas, embora tenha produzido colonização total de $95 \%$ nas mudas mantidas em solo da caatinga e $76 \%$ nas da área de empréstimo (Tabela 3 ). Esses valores superam os $28 \%$ encontrados em plantas de leucena que responderam à micorrização (SIQUEIRA e SAGGINJÚNIOR, 2001). Em experimento paralelo, utilizando sementes de leucena da mesma origem, aquele isolado de G. etunicatum promoveu o crescimento de mudas em substrato com até $50 \%$ de solo da subárea de rejeito (LINS et al., 2006). Entre as espécies de FMA avaliadas por Koffa e De La Cruz (1995), G. etunicatum também foi eficiente em promover o crescimento de leucena em solo deficiente de fósforo - $\mathrm{P}$ e tratado com sulfato de alumínio.

Avaliando a eficiência micorrízica dos FMA introduzidos em relação ao controle (FMA nativos), verificou-se que G. etunicatum foi eficaz (32\%) apenas para as mudas mantidas nos solos da caatinga (Tabela 4). Há relatos de maior eficiência de FMA nativos em comparação com introduzidos,

R. Árvore, Viçosa-MG, v.31, n.2, p.355-363, 2007 
como para Mimosa caesalpinifolia Benth (PRALON e MARTINS, 2001). No entanto, fungos introduzidos (G. clarum e Gigaspora margarita W.N. Becker e I.R. Hall) foram mais eficazes em promover o crescimento de mudas de duas leguminosas arbóreas tropicais [Piptadenia gonoacantha (Mart.) Macbr. e P. paniculata Benth.], as quais apresentaram dificuldade para crescer em substratos esterilizados (JESUS et al., 2005). No presente trabalho, mudas associadas à A. longula e mistura de FMA foram eficientes em promover o crescimento de mudas de leucena nos substratos estudados. Esses dados indicam que a resposta de crescimento varia de acordo com os genótipos da planta e do FMA e das condições nutricionais do substrato utilizado.

Quadro 3 - Colonização total e por vesículas e arbúsculos, em raízes de Leucaena leucocephala, após 110 dias da inoculação com fungos micorrízicos arbusculares (FMA), em solo da caatinga e substratos degradados por mineração de cobre

Table 3 - Total, vesicular and arbuscular colonization of roots of Leucaena leucocephala, 110 days after inoculation with arbuscular mycorrhizal fungi $(A M F)$, in caatinga soil and in substrates degraded by copper mining

\begin{tabular}{|c|c|c|c|c|}
\hline \multirow[t]{2}{*}{ Subárea } & \multicolumn{4}{|c|}{ Tratamento de Inoculação } \\
\hline & $\begin{array}{c}\text { Controle } \\
\text { (FMA nativos) }\end{array}$ & G. etunicatum & A. longula & $\begin{array}{c}\text { Mistura de FMA } \\
\text { (G. etunicatum }+ \text { A. longula) } \\
\end{array}$ \\
\hline & \multicolumn{4}{|c|}{ Colonização micorrízica total (\%) } \\
\hline Caatinga & $87,2 \mathrm{aA}$ & $95,2 \mathrm{aA}$ & $92,0 \mathrm{aA}$ & $94,0 \mathrm{aA}$ \\
\hline Empréstimo & $82,4 \mathrm{aA}$ & $76,0 \mathrm{bA}$ & $83,6 \mathrm{aA}$ & $62,4 \mathrm{bA}$ \\
\hline Rejeito & $0,0 \mathrm{bA}$ & $0,0 \mathrm{cA}$ & $0,0 \mathrm{bA}$ & $0,0 \mathrm{cA}$ \\
\hline \multirow[t]{2}{*}{$\mathrm{CV}(\%)$} & \multicolumn{4}{|c|}{16,5} \\
\hline & \multicolumn{4}{|c|}{ Colonização por vesículas (\%) } \\
\hline Caatinga & $70,4 \mathrm{aA}$ & $67,2 \mathrm{aA}$ & $61,6 \mathrm{aA}$ & $54,8 \mathrm{aA}$ \\
\hline Empréstimo & $24,8 \mathrm{bA}$ & $37,6 \mathrm{aA}$ & $26,8 \mathrm{bA}$ & $20,8 \mathrm{bA}$ \\
\hline Rejeito & $0,0 \mathrm{cA}$ & $0,0 \mathrm{bA}$ & $0,0 \mathrm{cA}$ & $0,0 \mathrm{cA}$ \\
\hline \multirow[t]{2}{*}{$\overline{\mathrm{CV}(\%)}$} & \multicolumn{4}{|c|}{30,8} \\
\hline & \multicolumn{4}{|c|}{ Colonização por arbúsculos (\%) } \\
\hline Caatinga & $11,6 \mathrm{aA}$ & $11,6 \mathrm{aA}$ & $6,0 \mathrm{aA}$ & $8,8 \mathrm{aA}$ \\
\hline Empréstimo & $6,0 \mathrm{aA}$ & $1,2 \mathrm{aA}$ & $2,8 \mathrm{aA}$ & $6,0 \mathrm{aA}$ \\
\hline Rejeito & $0,0 \mathrm{bA}$ & $0,0 \mathrm{bA}$ & $0,0 \mathrm{bA}$ & $0,0 \mathrm{bA}$ \\
\hline
\end{tabular}

Valores seguidos das mesmas letras, maiúsculas nas linhas e letras minúsculas nas colunas, dentro de cada variável, não diferem entre si pelo teste LSD a $5 \%$ de probabilidade.

Quadro 4 - Eficiência micorrízica estabelecida por fungos micorrízicos arbusculares (FMA) introduzidos, isoladamente ou em mistura, em mudas de Leucaena leucocephala, após 110 dias da inoculação em solo da caatinga e substratos degradados por mineração de cobre

Table 4 - Mycorrhizal efficiency established by introduced arbuscular mycorrhizal fungi(AMF), singly or in mixture, in seedlings of Leucaena leucocephala, 110 days after inoculation in caatinga soil and in substrates degraded by copper mining

\begin{tabular}{lccc}
\hline Subárea & \multicolumn{3}{c}{ Eficiência micorrízica (\%) } \\
\cline { 2 - 4 } & G. etunicatum & A. longula & $\begin{array}{c}\text { Mistura de FMA } \\
\text { (G. etunicatum + A. longula) }\end{array}$ \\
\hline Caatinga & 32,01 & 32,54 & 33,52 \\
Empréstimo & $-3,05$ & 31,08 & 29,95 \\
Rejeito & $-12,50$ & 14,79 & 36,00 \\
\hline
\end{tabular}

\section{R. Árvore, Viçosa-MG, v.31, n.2, p.355-363, 2007}




\section{CONCLUSÕES}

- Raízes de leucena não são colonizadas por FMA quando cultivadas em substrato de rejeito de área com mineração de cobre $\left(\geq 483 \mathrm{mg} \mathrm{dm}^{-3}\right)$.

- FMA nativos de áreas de caatinga preservadas ou impactadas por mineração de cobre e FMA introduzidos são igualmente capazes de colonizar raízes de leucena.

- O uso associado de A. longula isoladamente ou em mistura com $G$. etunicatum pode constituir alternativa para a produção de mudas de leucena em substrato contaminado por cobre (até $7,4 \mathrm{mg} \mathrm{dm}^{-3}$ ).

\section{AGRADECIMENTOS}

À Mineradora Caraíba S.A. e à Embrapa SemiÁrido (Laboratório de Solos), pelo apoio nas coletas e análise dos solos; ao Dr. Gladstone Alves da Silva, pelas sugestões; e à CAPES e ao CNPq, pelo continuado apoio.

\section{REFERÊNCIAS}

BAGYARAJ, D.J.; MANJUNATH, A.; GOVINDA RAO, Y.S. Mycorrhizal inoculation effect on marigold, eggplant and citrus in an Indian soil. Journal of Soil Biology e Ecology, v.8, p.48-103, 1988.

BRANDON, N.J.; SHELTON, H.M. Factors affecting the early growth of Leucaena leucocephala. Australian Journal of Experimental Agriculture, v.37, p.27-34, 1997.

CAMPELLO, E.F.C. Sucessão vegetal na recuperação de áreas degradadas. In: DIAS, L.E.; MELlo, J.W.V. (Ed.). Recuperação de Áreas Degradadas. Viçosa, MG: Universidade Federal de Viçosa / Sociedade Brasileira de Recuperação de Áreas Degradadas, 1998. p.183-196.

CAPRONI, A.L. et al. Fungos micorrízicos arbusculares em estéril revegetado com Acacia mangium, após mineração de bauxita. Revista Árvore, v.29, p. 373-381, 2005.
DEL VAL, C.; BAREA, J.M.; AZCÓN-AGUILAR, C. Assessing the tolerance to heavy metals of arbuscular mycorrhizal fungi isolated from sewage sludge-contaminated soils. Applied Soil Ecology, v.11, p.261-269, 1999.

DIAGNE, O. et al. Mycorrhizal inoculum potential of soils from alley cropping plots in Sénegal.

Forest Ecology and Management, v.1-3, p.35-43, 2001.

DIAS, L.E. Caracterização de substratos para fins de recuperação de áreas degradadas. In: DIAS, L.E.; MELLO, J.W.V. (Ed.). Recuperação de Áreas Degradadas. Viçosa, MG: Universidade Federal de Viçosa e Sociedade Brasileira de Recuperação de Áreas Degradadas, 1998. p.27-44.

DRUMOND, M.A. et al. Estratégias para o uso sustentável da biodiversidade da caatinga. In: SILVA, J.M.C et al. (Coord.). Biodiversidade da caatinga: áreas e ações prioritárias para a conservação. Brasília: Ministério do meio Ambiente / Universidade Federal de Pernambuco, 2004. p. 329-340.

DUPONNOIS, R. et al. Functional diversity of soil microbial community, rock phosphate dissolution and growth of Acacia seyal as influenced by grass, litter and soil-feeding termite nest structure amendments. Geoderma, v.124, p.349-361, 2005.

EMPRESA BRASILEIRA DE PESQUISA AGROPECUÁRIA - EMBRAPA. Centro Nacional de Pesquisa de Solos. Manual de métodos de análise do solo. Rio de Janeiro: 1997. 212p.

FAGBOLA, O. et al. Effects of drought stress and arbuscular mycorrhiza on the growth of Gliricidia sepium (Jacq). Walp, and Leucaena leucocephala (Lam.) de Wit. in simulated eroded soil conditions. Mycorrhiza, v.11, p.215-223, 2001.

GERDEMANN, J.W.; NICOLSON, T.H. Spores of mycorrhizal Endogone species extracted from soil by wet-sieving and decanting. Transactions of the British Mycological Society, v.46, p.235-244, 1963.

R. Árvore, Viçosa-MG, v.31, n.2, p.355-363, 2007 
GIOVANNETTI, M.; MOSSE, B. An evaluation of techniques for measuring vesicular arbuscular mycorrhizal infection in roots. New

Phytologist, v.84, p.489-500, 1980.

GRIFFIOEN, W.A.J.; JETSWAART, J.H.; ERNST, W.H.O. Mycorrhizal infection of an Agrostis capillaris population on a copper contaminated soil. Plant and Soil, v.158, p.83-89, 1994.

HABTE M.; MANJUNATH, A. Soil solution phosphorus status and mycorrhizal dependency in Leucaena leucocephala. Applied Environmental Microbiology, v.53, p.797-801, 1987.

INGLEBY, O. et al. Distribution of roots, arbuscular mycorrhizal colonisation and spores around fast-growing tree species in Senegal.

Forest Ecology and Management, v.90, p.19-27, 1997.

JENKINS, W.R. A rapid centrifugal-flotation technique for separating nematodes from soil. Plant Disease Reporter, v.48, p.692, 1964.

JESUS, E.C.; SCHIAVO, J. A.; FARIA, S.M. Dependência de micorrizas para a nodulação de leguminosas arbóreas tropicais. Revista Árvore, v.29, p.545-552, 2005.

KHAN, A.G. Relationships between chromium biomagnefication ratio, accumulation factor, and mycorrhiza in plants growing on tannery effluentpolluted-soil. Environment International, v.26, p.417-423, 2001.

KOFFA, S.N.; DE LA CRUZ, R.E. Screenhouse performance of VAM-inoculated seedlings of Leucaena leucocephala (Lam.) de Wit. in a phosphorus-deficient and aluminum sulfatetreated medium. New Forests, v.9, p.239-279, 1995.

KOSKE, R.E.; GEMMA, J.N. A modified procedure for staining roots to detect VA mycorrhizas.

Mycological Research, v.92, p.486-488, 1989.

LINS, C.E.L. et al. Growth of mycorrhized seedlings of Leucaena leucocephala (Lam.) de Wit. in a copper contaminated soil. Applied Soil Ecology, v.31, p.181-185, 2006.

R. Árvore, Viçosa-MG, v.31, n.2, p.355-363, 2007
MA, Y.; DICKINSON, N.M.; WONG, M.H. Beneficial effects of earthworms and arbuscular mycorrhizal fungi on establishment of leguminous trees on $\mathrm{Pb} / \mathrm{Zn}$ mine tailings. Soil Biology and Biochemistry, v.38, p.1403-1412, 2006.

MAIA, L.C.; TRUFEM, S.F.B. Fungos micorrízicos vesículo-arbusculares em solos cultivados no Estado de Pernambuco, Brasil. Revista Brasileira de Botânica, v.13, p.89-95, 1990.

MUTHUKUMAR, T; UDAIYAN, K. The role of seed reserves in arbuscular mycorrhizal formation and growth of Leucaena leucocephala (Lam.) de Wit. and Zea mays L. Mycorrhiza, v.9, p.323-330, 2000.

\section{PARROTA, J. A. Leucaena leucocephala}

(Lam.) de Wit. Leucaena, tantan. New Orleans: U.S. Department of Agriculture, Forest Service, Southern Forest Experiment Station. 1992. 8p.

PRALON, A.Z.; MARTINS, M.A. Utilização do resíduo industrial Ferkal na produção de mudas de Mimosa caesalpinifolia, em estéril de extração de argila, inoculadas com fungos micorrízicos arbusculares e rizóbio. Revista Brasileira de Ciência do Solo, v.25, p.55-63, 2001.

RAO, A.V.; TARAFDAR, J.C. Significance of micro-organisms in afforestation programmes in arid zone. Annals of Arid Zone, v. 37, p.337-346, 1998.

RODAL, M.J.; SAMPAIO, E.V.S.B. A vegetação do bioma caatinga. In: SAMPAIO, E.V.S.B. et al. (Ed.). Vegetação e flora da caatinga. Recife: Associação de Plantas do Nordeste-APNE, Centro Nordestino de Informações sobre Plantas-CNIP, 2002. p.11-24.

SCHENCK, N.C.; SIQUEIRA, J.O. Ecology of VA mycorrhizal fungi in temperate agroecosystems. In: SYLVIA, D.M.; HUNG, L.L.; GRAHAM, J.H. (Ed.). Mycorrhizae in the next decade: practical applications and research priorities. Gainesville: Institute of Food and Agricultural Sciences / University of Florida, 1987. p.2-4. 
SILVA, G.A. et al. Potencial de infectividade de fungos micorrízicos arbusculares oriundos de áreas de caatinga nativa e degradada por mineração, no Estado da Bahia, Brasil. Revista Brasileira de Botânica, v.24, p.135-143, 2001.

SILVA, G.A. et al. Arbuscular mycorrhizal fungi in a semiarid copper mining área in Brazil.

Mycorrhiza, v.15, p.47-53, 2005.

SIQUEIRA, J.O.; POUYÚ, E.; MOREIRA, F.M.S.

Micorrizas arbusculares no crescimento póstransplantio de mudas de árvores em solo com excesso de metais pesados. Revista Brasileira de Ciência do Solo, v.23, p.569-580, 1999.
SIQUEIRA, J.O.; SAGGIN-JÚNIOR, O.J. Dependency on arbuscular mycorrhizal fungi and responsiveness of some Brasilian native woody species. Mycorrhiza, v.11, p.245-255, 2001.

STADDON, P.L.; FITTER, A.H. The differential vitality of intraradical mycorrhizal structures and its implications. Soil Biology and Biochemistry, v.33, p.129-132, 2001.

STATSOFT. Statistic for Windows 95. General Convertions and Statistics 1. Oklahoma: Statsoft Incorporations, 1995. v.1. 